\title{
INSTIs and NNRTIs Potently Inhibit HIV-1 Polypurine Tract Mutants in a Single Round Infection Assay
}

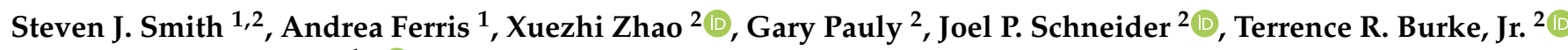 \\ and Stephen H. Hughes $1, *(\mathbb{D}$ \\ 1 HIV Dynamics and Replication Program, Center for Cancer Research, National Cancer Institute, \\ Frederick, MD 21702, USA; smithsj2@mail.nih.gov (S.J.S.); andrea.ferris@nih.gov (A.F.) \\ 2 Chemical Biology Laboratory, Center for Cancer Research, National Cancer Institute, \\ Frederick, MD 21702, USA; xuezhi.zhao@nih.gov (X.Z.); pauly@ncifcrf.gov (G.P.); \\ joel.schneider@nih.gov (J.P.S.); burkete@mail.nih.gov (T.R.B.J.) \\ * Correspondence: hughesst@mail.nih.gov
}

Citation: Smith, S.J.; Ferris, A.; Zhao, X.; Pauly, G.; Schneider, J.P.; Burke, T.R., Jr.; Hughes, S.H. INSTIs and NNRTIs Potently Inhibit HIV-1 Polypurine Tract Mutants in a Single Round Infection Assay. Viruses 2021, 13, 2501. https://doi.org/10.3390/ v13122501

Academic Editor: Gilda Tachedjian

Received: 2 November 2021

Accepted: 4 December 2021

Published: 14 December 2021

Publisher's Note: MDPI stays neutral with regard to jurisdictional claims in published maps and institutional affiliations.

Copyright: (c) 2021 by the authors. Licensee MDPI, Basel, Switzerland. This article is an open access article distributed under the terms and conditions of the Creative Commons Attribution (CC BY) license (https:// creativecommons.org/licenses/by/ $4.0 /)$.

\begin{abstract}
Integrase strand transfer inhibitors (INSTIs) are a class of antiretroviral compounds that prevent the insertion of a DNA copy of the viral genome into the host genome by targeting the viral enzyme integrase (IN). Dolutegravir (DTG) is a leading INSTI that is given, usually in combination with nucleoside reverse transcriptase inhibitors (NRTIs), to treat HIV-1 infections. The emergence of resistance to DTG and other leading INSTIs is rare. However, there are recent reports suggesting that drug resistance mutations can occur at positions outside the integrase gene either in the HIV-1 polypurine tract (PPT) or in the envelope gene (env). Here, we used single round infectivity assays to measure the antiviral potencies of several FDA-approved INSTIs and non-nucleoside reverse transcriptase inhibitors (NNRTIs) against a panel of HIV-1 PPT mutants. We also tested several of our promising INSTIs and NNRTIs in these assays. No measurable loss in potency was observed for either INSTIs or NNRTIs against the HIV-1 PPT mutants. This suggests that HIV-1 PPT mutants are not able, by themselves, to confer resistance to INSTIs or NNRTIs.
\end{abstract}

Keywords: inhibition; integration; resistance; efficacy; infectivity

\section{Introduction}

Integrase strand transfer inhibitors (INSTIs), when used in combination with nucleoside reverse transcriptase inhibitors (NRTIs), are the currently recommended treatment strategy for people living with HIV who are either treatment-naïve or treatmentexperienced [1]. Dolutegravir (DTG) and bictegravir (BIC) are potent INSTIs that comprise, together with cabotegravir (CAB), the second generation INSTIs. BIC and DTG retain high potencies against resistant mutants that arise in response to the first generation INSTIs raltegravir (RAL) and elvitegravir (EVG) [2-7]. When compared to RAL and EVG, the resistance profiles of DTG and BIC are much more favorable [8,9]. Only a few DTG- and BIC-resistant mutants have been identified either in selection studies in vitro or in HIVinfected individuals who are treatment-experienced [2,3,10,11]. Most mutations that are selected by antiretroviral drugs arise in the region that encodes the target protein [12]. For example, most drug-resistant mutations that arise in response to INSTIs are in the region of the pol gene that encodes IN. Although DTG and BIC are much less apt to select for resistance than RAL and EVG, the following mutations in IN were selected by DTG in an in vitro experiment: H51Y, T66A/I, G118R, E138K, S153Y/F, and R263K [2,13-15]. In addition, the M50I, S153Y/F, R263K, and M50I/R263K mutations in IN were selected by $\mathrm{BIC}$ [3]. Resistance mutations have been selected in vitro in the presence of CAB primarily at position Q148R/K. Several additional mutations emerged when viruses with amino acid substitutions at position Q148K/R and an additional IN mutant, Q148H, were passaged 
in cells in culture [16-18]. The Q148R mutant in IN was also selected in two people living with HIV who were in clinical trials that included CAB [19].

A recent study, using DTG selection in vitro, identified mutations in the HIV-1 polypurine tract (PPT) [20]. The PPT mutations were reported to confer resistance to DTG. Similar mutations in the HIV-1 PPT were reported to have been selected in a HIV-1 treatmentexperienced subject who failed a DTG monotherapy maintenance regimen [21]. It has also been recently reported that mutations in the HIV-1 envelope glycoprotein (Env) can confer resistance to both DTG and RAL in multicycle spreading infections in cultured cells $[22,23]$. These reports suggest that it may be easier for HIV to develop resistance to the most potent and broadly effective INSTIs by acquiring mutations outside of the IN-coding region. However, the mechanisms underlying resistance that involve mutations outside the region that encodes the target protein are not well-defined.

Recently, a phenotypic analysis was performed to determine the susceptibility of HIV-1 PPT mutants to INSTIs (RAL, EVG, DTG, and CAB) and non-nucleoside reverse transcriptase inhibitors (NNRTIs) [efavirenz, (EFV) and rilpivirine (RPV)] [24]. This study suggested that the FDA-approved INSTIs and NNRTIs retain efficacy against two HIV-1 PPT mutants and concluded that these PPT mutations do not confer resistance to either class of drugs. To help resolve these conflicting reports, we determined the $\mathrm{EC}_{50}$ values of all the FDA-approved INSTIs, for the leading FDA-approved NNRTIs, and for several of our potent INSTI leads (Figure 1) and NNRTI leads (Figure 2) against a panel of HIV1 PPT mutants that have been reported to confer resistance in a single round infection assay. We show that all of the INSTIs and NNRTIs we tested retained their potency against the HIV-1 PPT mutants. Additionally, the HIV-1 PPT mutants replicated poorly in single-round infection assays when compared to WT HIV-1. Our results show that the HIV-1 PPT mutants do not confer resistance to either INSTIs or NNRTIs in a single-round infection assay.
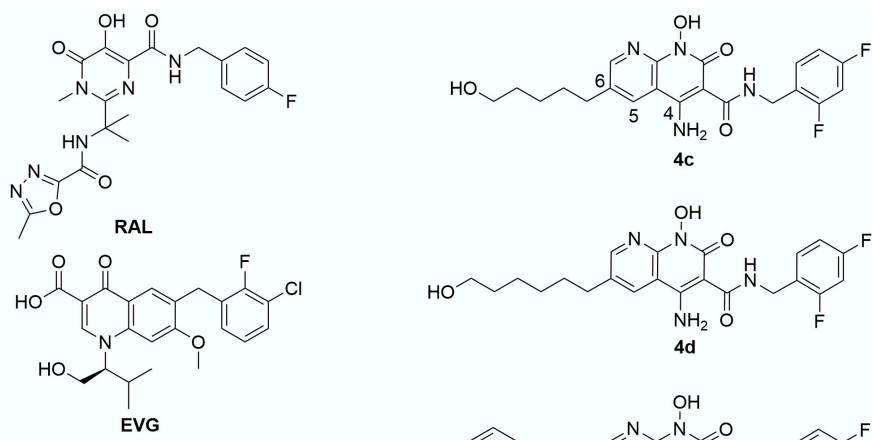

$4 \mathrm{c}$
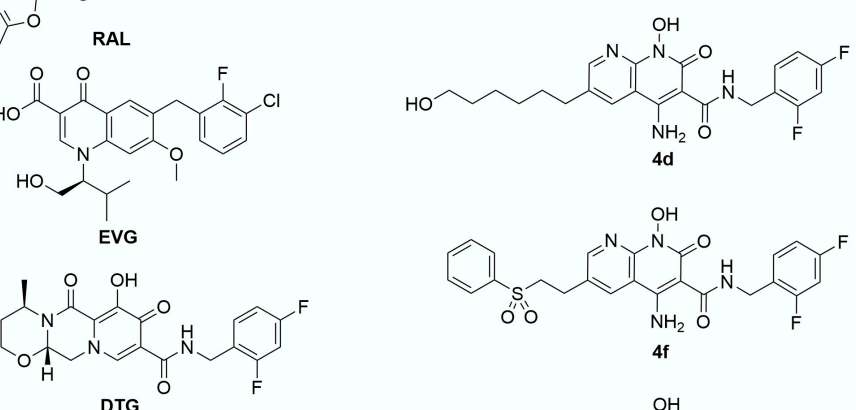

$4 \mathrm{f}$

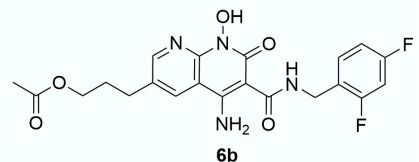

BIC

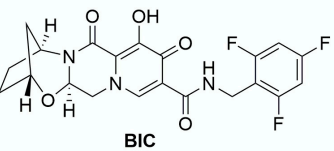

$6 \mathrm{~b}$
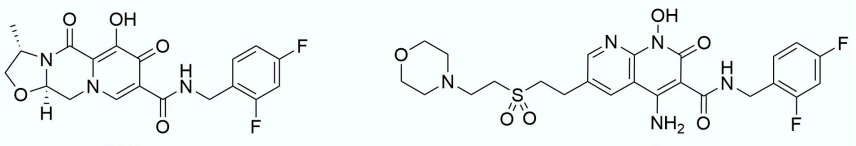

CAB

$6 \mathrm{v}$

Figure 1. Chemical structures of the INSTIs. The chemical structures of the INSTIs used in this study are shown. 

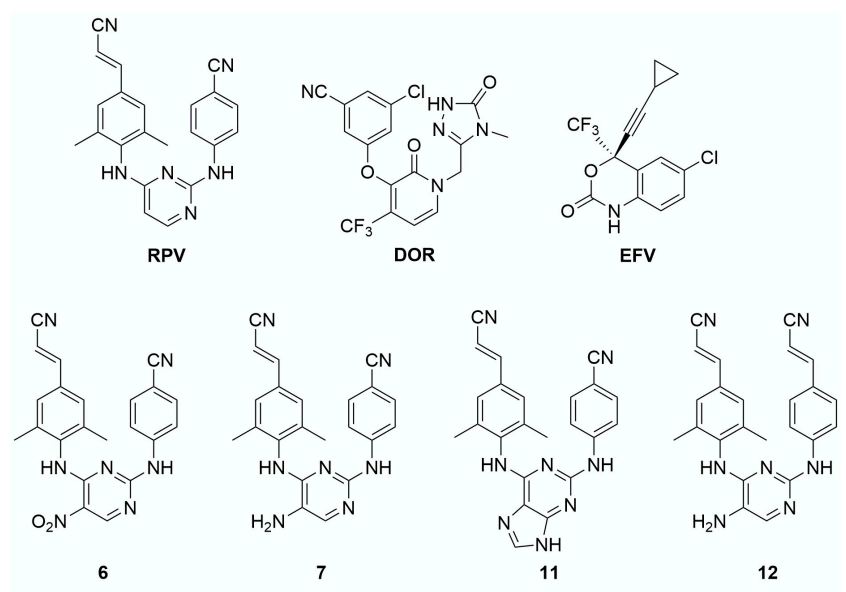

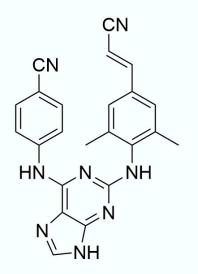

13

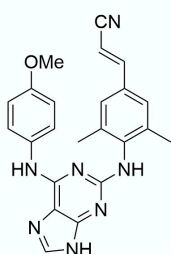

16

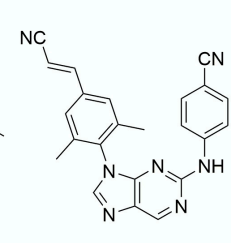

27

Figure 2. Chemical structures of the NNRTIs. The chemical structures of the NNRTIs used in this study are shown.

\section{Materials and Methods}

Vector constructs. The pNLNgoMIVR-Emod Luc vector has been described [25]. To generate the mutations used in this study, a $1.7 \mathrm{~Kb}$ XhoI-NcoI digested fragment containing the PPT was excised from pNLNgoMIVR-Emod Luc and subcloned into pET-32a(+). The resulting plasmid served as the template for site-directed mutagenesis (QuickChange II XL kit, Agilent Technologies, Santa Clara, CA, USA) of the poly G tract (GGGGGG) using the following sense oligonucleotides with matching cognate antisense oligonucleotides (not shown) (Integrated DNA Technologies, Coralville, IA):

AGC (GGGAGC), 5'-CCACTTTTTAAAAGAAAAGGGAGCACTGGAAGGGCTAATTC-3'; AGT (GGGAGT), 5'-CCACTTTTTAAAAGAAAAGGGAGTACTGGAAGGGCTAATTC-3'; +G (GGGGAGT), 5'-CCACTTTTTAAAAGAAAAGGGGAGTACTGGAAGGGCTAATTC-3'; +G (GGGGAGT), 5'-CCACTTTTTAAAAGAAAAGGGGAGTACTGGAAGGGCTAATTC-3'; $\Delta \mathrm{G}$ (_GCAGT), 5'-CCACTTTTTAAAAGAAAAGCAGTACTGGAAGGGCTAATTC-3'; AGTG (GGAGTG)' 5'-CCACTTTTTAAAAGAAAAGGAGTGACTGGAAGGGCTAATTC-3' .

Sequences of the mutated inserts were verified by DNA sequencing, and the XhoINcol fragment was excised from each mutated plasmid and inserted into identically digested pNLNgoMIVR-Emod Luc.

Cell-based assays. The $\mathrm{EC}_{50}$ values of the compounds were measured using either WT HIV-1 or the HIV-1 PPT mutants in single-round infectivity assays as described previously $[26,27]$. Briefly, a VSV-g-pseudotyped HIV vector was produced by transfections of 293 T cells with pNLNgoMIVR-Emod $\Delta$ LUC and pHCMV-g (obtained from Dr. Jane Burns, University of California, San Diego, CA, USA) using the calcium phosphate method. Approximately $6 \mathrm{~h}$ after the calcium phosphate precipitate was added, the transfected cells were washed twice with phosphate-buffered saline (PBS) and incubated with fresh media for $48 \mathrm{~h}$. The virus-containing supernatants were then harvested, clarified by low-speed centrifugation, filtered, and diluted for use in antiviral infection assays. On the day prior to the assay, HOS cells were seeded in a 96-well luminescence cell culture plate at a density of 4000 cells in $100 \mu \mathrm{L}$ per well. On the day of the assay, cells were treated with compounds over a range of concentrations from $5 \mu \mathrm{M}$ to $0.0001 \mu \mathrm{M}$ using 11 serial dilutions. After a $3 \mathrm{~h}$ preincubation with the compounds, $100 \mu \mathrm{L}$ of virus-stock was added. The virus was diluted to achieve a luciferase signal between 0.2 and 2.0 Relative Luciferase Units 
(RLUs). The cells were incubated at $37^{\circ} \mathrm{C}$ for $48 \mathrm{~h}$. Infectivity was measured by using the Steady-lite plus luminescence reporter gene assay system (PerkinElmer, Waltham, MA, USA). Luciferase activity was measured by adding $100 \mu \mathrm{L}$ of Steady-lite plus buffer (PerkinElmer) to the cells, incubating at room temperature for $20 \mathrm{~min}$, and measuring luminescence using a microplate reader. Antiviral activities were normalized to the infectivity in cells in the absence of target compounds. KaleidaGraph (Synergy Software, Reading, PA, USA) was used to perform non-linear regression analysis on the data. $\mathrm{EC}_{50}$ values were determined from the fit model. The luciferase activity of the WT virus was set to $100 \%$, and the infectivity of the mutant viruses was measured as a percentage of WT.

INSTI and NNRTI synthesis. RAL, EVG, DTG, BIC, and CAB were acquired as described previously $[4,28]$. The preparation of compounds $4 \mathbf{c}, 4 \mathbf{d}, 4 \mathbf{f}, \mathbf{6 b}$, and $\mathbf{6 v}$ was done by previously reported procedures $[27,29,30]$. EFV, RPV, and doravirine (DOR) were acquired as previously described [31,32]. The preparation of compounds 6, 7, 11, 12, 13, 16, and 27 has been reported [32,33].

\section{Results}

HIV-1 PPT mutants. Recent reports suggested that there are several different mutations in the HIV-1 PPT that can cause resistance to DTG $[20,21]$. An in vitro selection study identified several HIV-1 PPT mutations within the "poly G tract", (GGGGGG) and a clinical study reported that a patient who suffered virological failure during DTG maintenance therapy had two mutations in the poly G tract, GGGAGC. Using the reported sequences of the mutant PPTs as guides, we made the following HIV-1 mutants that had changes in the poly G tract of the PPT (Figure 3): AGC (GGGAGC), AGT (GGGAGT), +G (GGGGAGT), $\Delta G$ (_GCAGT), and AGTG (GGAGTG).

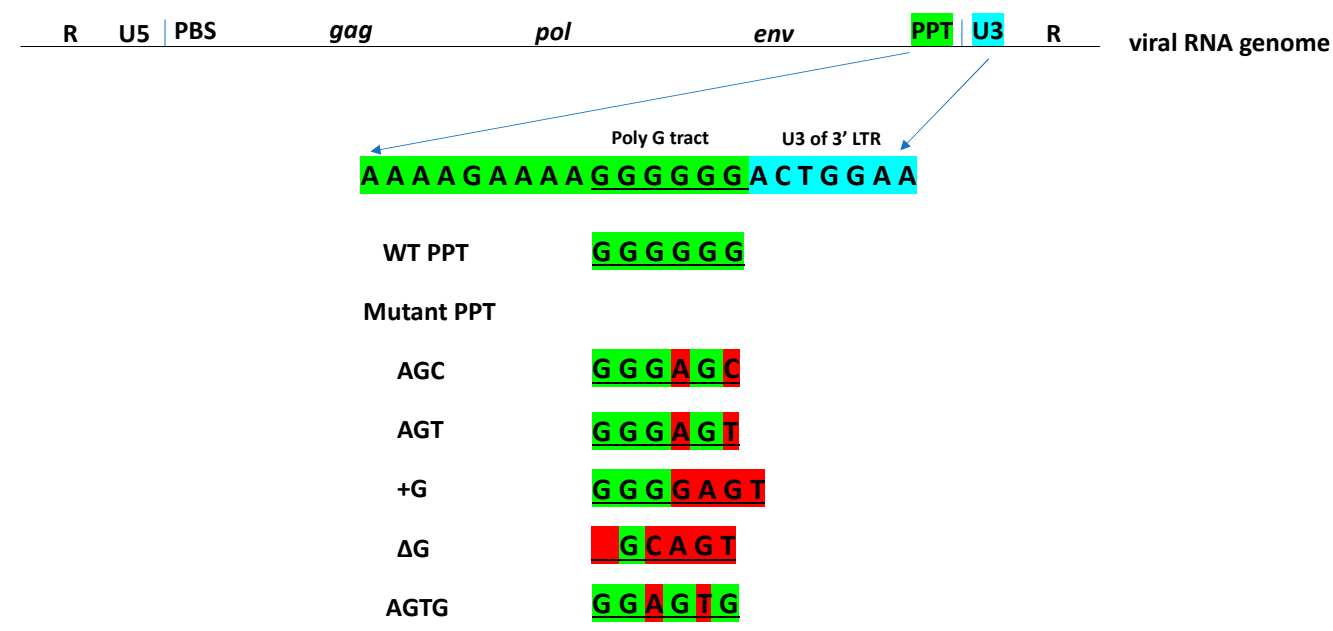

Figure 3. Design and construction of HIV-1 PPT mutants. Sequences of the HIV-1 PPT mutants. A schematic showing the mutations in the HIV-1 PPT. The HIV-1 PPT, which is highlighted in green, is adjacent to the U3 of the $3^{\prime}$ LTR (highlighted in cyan). The sequences of the HIV-1 PPT mutants are shown. The mutations, which are in in the poly $\mathrm{G}$ tract, are highlighted in red.

Replication of the HIV-1 PPT mutants in a single-round infection assay. In general, INSTI-resistant mutants have a reduced ability to replicate when compared to WT HIV1 [27,28,34]. To determine the degree to which the mutations in the HIV-1 PPT effect HIV-1 replication, we measured the replication of the HIV-1 PPT mutants and WT HIV-1 in single-round infection assays (Table 1). 
Table 1. Replication of the HIV-1 PPT mutants using a single round infection assay.

\begin{tabular}{cc}
\hline PPT Mutant & Single Round Infectivity (\% of WT Activity) \\
\hline AGC & $5.0 \pm 1.2$ \\
AGT & $7.0 \pm 1.4$ \\
$+G$ & $8.0 \pm 2.5$ \\
$\Delta$ AGTG & $0^{*}$ \\
\hline
\end{tabular}

* Single round infectivities for $\Delta \mathrm{G}$ and AGTG could not be determined.

Table 1 Replication of the HIV-1 PPT mutants using a single-round infection assay. Replication of the HIV-1 PPT mutants used in single-round infection assay. The abilities of the HIV-1 PPT mutants to replicate, compared with WT HIV-1, were measured in a single-round infection assay using vectors carrying the appropriate mutations. The relative luciferase activity for the WT HIV-1 virus in the absence of antiretroviral drugs was set to $100 \%$, and infections by the HIV-1 vectors with the mutant PPTs (adjusted for amount of p24/Gag used in the assay) were measured and compared to WT. An asterisk indicates that the $\Delta \mathrm{G}$ and AGTG did not replicate to a measurable extent in the assay.

All five of the HIV-1 PPT mutants were significantly less able to infect cells in a singleround assay relative to WT HIV-1. When compared to the replication of WT HIV-1 (100\%), the AGC PPT mutant had a single round infectivity of $5.0 \%$. The AGT and $+\mathrm{G}$ mutants had single-round infectivities of $7.0 \%$ and $8.0 \%$, respectively. The additional PPT mutants we tested, $\triangle \mathrm{G}$ and AGTG, did not infect cells to a measurable extent in our single-round assay. Our in vitro results suggest that the PPT mutants would probably replicate poorly in people living with HIV. However, Wei and Sluis-Cremer [35] reported that HIV carrying the mutant PPT we call AGC (which they call PPT2) replicated well in cultured cells. The virus/vectors are different, as are the assays; however, we cannot account for this apparent discrepancy.

Antiviral potencies of INSTIs against a panel of HIV-1 PPT mutants. Recent reports presented conflicting results on the susceptibility of HIV-1 PPT mutants to INSTIs [20,24]. To determine if there is a measurable loss in potency for INSTIs against the HIV-1 PPT mutants, the $\mathrm{EC}_{50}$ values were determined in single-round infection assays. We tested all five FDA-approved INSTIs, BIC, DTG, CAB, RAL, and EVG, and several of our most promising INSTIs: $\mathbf{4 c}, \mathbf{4 c}, \mathbf{4 f}, \mathbf{6} \mathbf{p}$, and $\mathbf{6 v}$ against WT HIV-1 and the HIV-1 PPT mutants AGC, AGT, and +G (Figure 4, Table S1).

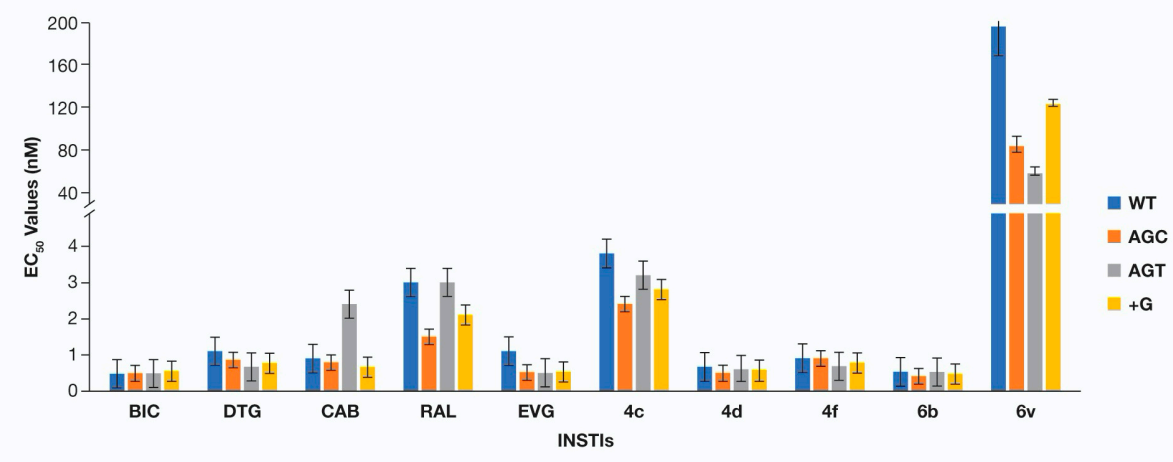

Figure 4. Antiviral potencies of INSTIs against a panel of HIV-1 PPT mutants. The EC 50 values were determined using a vector that carries either a WT PPT or one of the HIV-1 PPT mutants in a single-round infection assay. The $Y$-axis, which depicts the $\mathrm{EC}_{50}$ value, is broken between 4 and $40 \mathrm{nM}$, and is set to a maximum of $200 \mathrm{nM}$. Error bars represent the standard deviation of the independent experiments, which were performed in triplicate.

All of the INSTIs we tested, except for $6 \mathrm{v}(195.0 \pm 27.2 \mathrm{nM})$, potently inhibited the replication of WT HIV-1 $(<4.0 \mathrm{nM})$. In agreement with the results of Wei and Sluis- 
Cremer [24], neither the FDA-approved INSTIs nor our compounds showed a loss of potency against the HIV-1 PPT mutants. When tested against the HIV-1 PPT mutant AGC, all of the INSTIs, except for $6 \mathrm{v}(85.4 \pm 7.5 \mathrm{nM})$, had $\mathrm{EC}_{50}$ values below $3.0 \mathrm{nM}$. Similarly, for the AGT mutant, the $\mathrm{EC}_{50}$ values for BIC, DTG, EVG, $\mathbf{4 d}, \mathbf{4 f}$, and $\mathbf{6} \mathbf{b}$ were all below $1.0 \mathrm{nM}$. $\mathrm{CAB}, \mathrm{RAL}$, and $4 \mathrm{c}$ had potencies ranging between 2.0 to $4.0 \mathrm{nM}$ for this HIV PPT mutant. Compound $6 \mathbf{v}$ was the least potent $(60.5 \pm 3.8 \mathrm{nM})$ against AGC. The HIV-1 PPT mutant $+\mathrm{G}$ did not display a reduction in susceptibility against the INSTIs tested. All INSTIs had $\mathrm{EC}_{50}$ values below $1.0 \mathrm{nM}$ against $+\mathrm{G}$, except for RAL $(2.1 \pm 0.3 \mathrm{nM}), 4 \mathrm{c}(2.8 \pm 0.5 \mathrm{nM})$ and $6 \mathbf{v}(123.9 \pm 3.3 \mathrm{nM})$. We saw no significant reduction in susceptibility to any of the HIV-1 PPT mutants we tested, using either the FDA-approved INSTIs or our compounds. The most consistent differences we saw were for $6 \mathbf{v}$. When compared to its $\mathrm{EC}_{50}$ value against WT (195.0 $\pm 27.2 \mathrm{nM}), 6 \mathbf{v}$ had a lower $\mathrm{EC}_{50}$ for all three HIV-1 PPT mutants, AGC, AGT and $+\mathrm{G}(85.4 \pm 7.5 \mathrm{nM}, 60.5 \pm 3.8 \mathrm{nM}$, and $123.9 \pm 3.3 \mathrm{nM}$, respectively). These differences suggest that the PPT mutants we tested may be slightly more susceptible to $6 \mathbf{v}$. However, the compound is not particularly potent, and the fold change in the $\mathrm{EC}_{50}$ is small (about 2-fold).

Comparison of antiviral potencies of NNRTIs against a panel of HIV-1 PPT mutants. It has been previously reported that RT-mediated plus strand DNA synthesis from the $3^{\prime}$ PPT is inhibited by NNRTIs [35-38]. To show that NNRTIs can still effectively inhibit HIV-1 replication, and, by extension, reverse transcription of the HIV-1 PPT mutants, we measured the $\mathrm{EC}_{50}$ values of the FDA-approved NNRTIs EFV, RPV, and DOR and several of our NNRTIs $(\mathbf{6}, \mathbf{7}, \mathbf{1 1}, \mathbf{1 2}, \mathbf{1 3}, \mathbf{1 6}$, and 27) against the HIV-1 PPT mutants AGC, AGT, and $+\mathrm{G}$ in a single-round infection assay (Figure 5, Table S2).

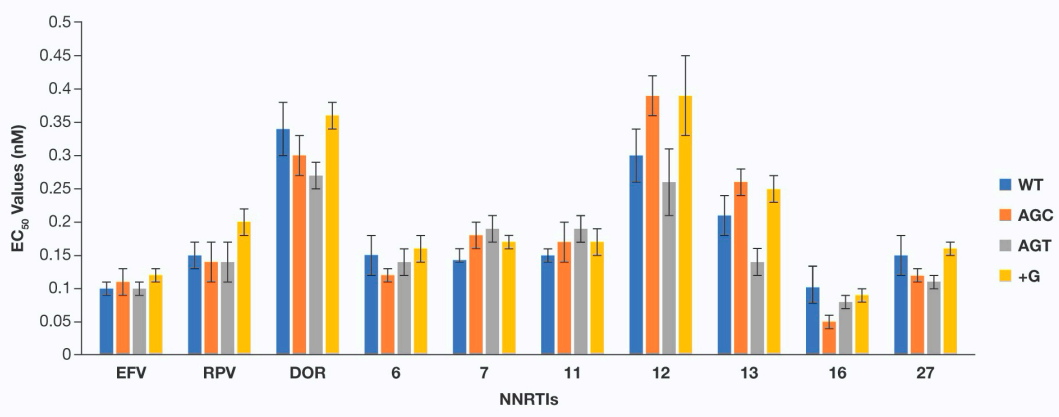

Figure 5. Antiviral potencies of NNRTIs against a panel of HIV-1 PPT mutants. The EC 50 values were determined using a vector that carries either a WT PPT or one of the HIV-1 PPT mutants in a single-round infection assay. The $Y$-axis, which depicts the $\mathrm{EC}_{50}$ value, is set to have a maximum of $0.5 \mathrm{nM}$. Error bars represent the standard deviation of the independent experiments, which were performed in triplicate.

We previously showed that the clinically relevant NNRTIs and several of our own NNRTIs exhibit subnanomolar $\mathrm{EC}_{50}$ values against WT HIV-1 [31-33]; the $\mathrm{EC}_{50}$ values measured in the assays performed for this report were similar. We saw no loss in potency when the FDA-approved NNRTIs and our promising NNRTIs were tested against the HIV-1 PPT mutants AGC, AGT, and +G. These data provide additional support for the conclusion that the HIV-1 PPT mutants do not confer significant resistance against either INSTIs or NNRTIs in single-round HIV-1 infection assays.

\section{Conclusions}

INSTIs have been used in the HIV-1 combination antiretroviral therapies that are currently recommended for either treatment-naïve or treatment-experienced individuals [1]. DTG and BIC potently inhibit WT HIV-1 and many of the signature RAL- and EVG-resistant mutants [2-7]. In addition, neither DTG nor BIC readily select new drug-resistant mutants. Resistance has been reported to arise against these INSTIs in vivo in treatment-experienced, 
INSTI-experienced individuals, who displayed virological failure in a RAL-containing regimen and were subsequently switched to a DTG-containing regimen [10,11]. However, there have been recent reports suggesting that there may be novel mechanisms of INSTI resistance that do not involve mutations in the region of pol that encodes IN. HIV-1 env mutants have been selected in vitro that broadly decrease the potencies of several types of anti-HIV drugs, including the INSTIs DTG and RAL, in multi-round in-vitro replication assays [22,23]. It has also been reported that mutations in the HIV-1 PPT were selected in vitro and that similar mutations were reported to have been selected in vivo in an individual who was failing a DTG maintenance monotherapy [20,21].

Here, we investigated whether the HIV-1 PPT mutants reduce the potencies of either INSTIs or NNRTIs in single-round infection assays. We measured $\mathrm{EC}_{50}$ values of the FDAapproved INSTIs and NNRTIs and several of our promising INSTIs and NNRTIs against a panel of HIV-1 PPT mutants. Neither the INSTIs nor the NNRTIs we tested showed a loss in potency against the HIV-1 PPT mutants, substantiating the results reported in a recent study [24]. In addition, when we tested the ability of the HIV-1 PPT mutants to replicate in single-round infection assays, all of the mutants we tested replicated poorly compared to WT HIV-1. Taken together, it seems likely that these HIV-1 PPT mutants do not provide significant levels of resistance to DTG or RAL.

These results are not surprising, given the nature of the IN strand transfer (ST) reaction. After the viral DNA is synthesized, a multimeric form of IN forms a complex with both ends of the newly synthesized linear viral DNA [39]. In the first step of the integration process called $3^{\prime}$-processing, IN removes a pair of nucleotides from each of the $3^{\prime}$-ends of the viral DNA $[40,41]$. In the second step, IN inserts the processed $3^{\prime}$ ends of the viral DNA into the host genome [42,43]. It is the second reaction, strand transfer, that is blocked by INSTIs.

The HIV-1 PPT, after being cleaved by the RNase H of RT, acts as the primer for second (positive) strand viral DNA synthesis [44]. Thus, the PPT plays a crucial role in reverse transcription, and mutations in the HIV-1 PPT can affect the specificity of the RNase $\mathrm{H}$ cleavage events [35]. This can, in turn, affect the sequence of the PPT primer. The sequence of the PPT primer defines where plus strand DNA synthesis is initiated, and, by extension, the sequences at the end of the upstream LTR in the linear viral DNA intermediate. IN may not be able to correctly process or integrate an abnormal linear viral DNA end. We previously showed that, if a viral DNA has one normal and one abnormal DNA end, the normal end can be integrated by IN, and the abnormal end can be inserted, with a reduced efficiency, by host enzymes [45]. The host-mediated integration event is abnormal and affects both the host and viral sequences at the junction. However, this type of abnormal viral/host integration event can lead to the creation of a provirus that can produce normal viral RNA. The published data strongly suggest that the host-mediated integration of the aberrant viral DNA end happens after the IN-mediated integration of the normal DNA end [46].

It is not clear how a PPT mutation would be able to protect the integration of the normal end of the linear viral DNA from an INSTI. The initial IN-mediated integration of the downstream end of the viral DNA should still be completely susceptible to inhibition by an INSTI. Even if the INSTI were to bind poorly to a complex of the aberrant viral DNA end bound to IN, IN would still have to be able to integrate the aberrant end reasonably efficiently. However, we know that the PPT mutants have a very low titer in the absence of an INSTI, which suggests that IN does not insert the mutant forms of the DNA made by the PPT mutants efficiently. The low titer of the PPT mutants was determined in the absence of an INSTI under conditions in which IN would be able to insert the normal end of the viral DNA efficiently. The titer of the virus would be further reduced if an INSTI were to block the integration of the normal end of the DNA. Thus, it is unclear how a PPT mutant could confer resistance to an INSTI.

Similar to INSTIs, we would not expect the HIV-1 PPT mutants to show a decrease in susceptibility to NNRTIs. NNRTIs inhibit DNA initiation for both the minus strand 
and plus strand during reverse transcription [38,47-49]. The minus strand transfer step and the RNase $\mathrm{H}$ cleavages that generate the PPT primer must occur before plus strand DNA synthesis is initiated. In addition, RT must make the entire minus strand DNA. NNRTIs should be able to inhibit the reverse transcription of the minus strand DNA in viruses that carry the HIV-1 PPT mutants. In addition, there are a number of mutations in HIV RT that can cause resistance to NNRTIs [50]. Changes in residues in and around the NNRTI binding pocket reduce the ability of RT to bind NNRTIs [32,33], making it less likely that NNRTIs would select for mutations outside the region of pol that encodes RT. Conversely, HIV has much more difficulty developing resistance to the second-generation INSTIs, particularly DTG and BIC [8].

Because it is difficult for HIV to develop resistance to the most potent second generation INSTIs, it is possible that the virus will develop mechanisms that do not involve changes in IN. There is good evidence that mutations in env can broadly reduce the susceptibility of HIV-1 to all antiviral drugs, including INSTIs, in a multi-round assay in vitro $[22,23]$. Although we think that all positions where resistance mutations have been reported to arise in the HIV-1 viral genome should be explored so that any novel mechanisms that could lead to treatment failure are fully explored, it does not appear that any of the reported PPT mutants confer resistance to INSTIs in single-round assays.

Supplementary Materials: The following are available online at https:/ / www.mdpi.com/article / 10.3390/v13122501/s1, Table S1: Comparison of antiviral potencies of INSTIs against a panel of HIV-1 PPT mutants, Table S2: Comparison of antiviral potencies of NNRTIs against a panel of HIV-1 PPT mutants.

Author Contributions: S.J.S. and S.H.H. designed the experiments; S.J.S. performed the experiments. A.F. prepared the vectors. X.Z. and G.P. prepared the compounds. S.J.S. and S.H.H. wrote the main manuscript. J.P.S. and T.R.B.J. helped edit and improve parts of manuscript. All authors have read and agreed to the current version of the manuscript.

Funding: Our studies are supported by the NIH Intramural Program, Center for Cancer Research, National Cancer Institute and by grants from the NIH AIDS Intramural Targeted Program (IATAP).

Institutional Review Board Statement: Not applicable.

Informed Consent Statement: Not applicable.

Data availability statement: The data presented in this study are available by request from the corresponding author.

Acknowledgments: The authors thank Terri Burdette for technical support and manuscript preparation.

Conflicts of Interest: The authors declare no conflict of interest.

\section{References}

1. Panel on Antiretroviral Guidelines for Adults and Adolescents. Guidelines for the Use of Antiretroviral Agents in Adults and Adolescents with HIV; U.S. Department of HHS: Washington, DC, USA, 2021.

2. Kobayashi, M.; Yoshinaga, T.; Seki, T.; Wakasa-Morimoto, C.; Brown, K.W.; Ferris, R.; Foster, S.A.; Hazen, R.J.; Miki, S.; SuyamaKagitani, A.; et al. In Vitro antiretroviral properties of S/GSK1349572, a next-generation HIV integrase inhibitor. Antimicrob. Agents Chemother. 2011, 55, 813-821. [CrossRef]

3. Tsiang, M.; Jones, G.S.; Goldsmith, J.; Mulato, A.; Hansen, D.; Kan, E.; Tsai, L.; Bam, R.A.; Stepan, G.; Stray, K.M.; et al. Antiviral Activity of Bictegravir (GS-9883), a Novel Potent HIV-1 Integrase Strand Transfer Inhibitor with an Improved Resistance Profile. Antimicrob. Agents Chemother. 2016, 60, 7086-7097. [CrossRef]

4. Smith, S.J.; Zhao, X.Z.; Burke, T.R., Jr.; Hughes, S.H. Efficacies of Cabotegravir and Bictegravir against drug-resistant HIV-1 integrase mutants. Retrovirology 2018, 15, 37. [CrossRef]

5. Hare, S.; Smith, S.J.; Metifiot, M.; Jaxa-Chamiec, A.; Pommier, Y.; Hughes, S.H.; Cherepanov, P. Structural and functional analyses of the second-generation integrase strand transfer inhibitor dolutegravir (S/GSK1349572). Mol. Pharmacol. 2011, 80, 565-572. [CrossRef]

6. Margot, N.A.; Ram, R.R.; White, K.L.; Abram, M.E.; Callebaut, C. Antiviral activity of HIV-1 integrase strand-transfer inhibitors against mutants with integrase resistance-associated mutations and their frequency in treatment-naive individuals. J. Med. Virol. 2019, 91, 2188-2194. [CrossRef] [PubMed] 
7. Zhao, X.Z.; Smith, S.J.; Metifiot, M.; Marchand, C.; Boyer, P.L.; Pommier, Y.; Hughes, S.H.; Burke, T.R., Jr. 4-amino-1-hydroxy2-oxo-1,8-naphthyridine-containing compounds having high potency against raltegravir-resistant integrase mutants of HIV-1. J. Med. Chem. 2014, 57, 5190-5202. [CrossRef] [PubMed]

8. Smith, S.J.; Zhao, X.Z.; Passos, D.O.; Lyumkis, D.; Burke, T.R., Jr.; Hughes, S.H. Integrase Strand Transfer Inhibitors Are Effective Anti-HIV Drugs. Viruses 2021, 13, 205. [CrossRef] [PubMed]

9. Rhee, S.Y.; Grant, P.M.; Tzou, P.L.; Barrow, G.; Harrigan, P.R.; Ioannidis, J.P.A.; Shafer, R.W. A systematic review of the genetic mechanisms of dolutegravir resistance. J. Antimicrob. Chemother. 2019, 74, 3135-3149. [CrossRef] [PubMed]

10. Castagna, A.; Maggiolo, F.; Penco, G.; Wright, D.; Mills, A.; Grossberg, R.; Molina, J.M.; Chas, J.; Durant, J.; Moreno, S.; et al. Dolutegravir in antiretroviral-experienced patients with raltegravir- and/or elvitegravir-resistant HIV-1: 24-week results of the phase III VIKING-3 study. J. Infect. Dis. 2014, 210, 354-362. [CrossRef]

11. Eron, J.J.; Clotet, B.; Durant, J.; Katlama, C.; Kumar, P.; Lazzarin, A.; Poizot-Martin, I.; Richmond, G.; Soriano, V.; Ait-Khaled, M.; et al. Safety and efficacy of dolutegravir in treatment-experienced subjects with raltegravir-resistant HIV type 1 infection: 24-week results of the VIKING Study. J. Infect. Dis. 2013, 207, 740-748. [CrossRef]

12. Collier, D.A.; Monit, C.; Gupta, R.K. The Impact of HIV-1 Drug Escape on the Global Treatment Landscape. Cell Host Microbe 2019, 26, 48-60. [CrossRef] [PubMed]

13. Brenner, B.G.; Thomas, R.; Blanco, J.L.; Ibanescu, R.I.; Oliveira, M.; Mesplede, T.; Golubkov, O.; Roger, M.; Garcia, F.; Martinez, E.; et al. Development of a G118R mutation in HIV-1 integrase following a switch to dolutegravir monotherapy leading to cross-resistance to integrase inhibitors. J. Antimicrob. Chemother. 2016, 71, 1948-1953. [CrossRef]

14. Quashie, P.K.; Mesplede, T.; Han, Y.S.; Oliveira, M.; Singhroy, D.N.; Fujiwara, T.; Underwood, M.R.; Wainberg, M.A. Characterization of the R263K mutation in HIV-1 integrase that confers low-level resistance to the second-generation integrase strand transfer inhibitor dolutegravir. J. Virol. 2012, 86, 2696-2705. [CrossRef] [PubMed]

15. Quashie, P.K.; Oliviera, M.; Veres, T.; Osman, N.; Han, Y.S.; Hassounah, S.; Lie, Y.; Huang, W.; Mesplede, T.; Wainberg, M.A. Differential effects of the G118R, H51Y, and E138K resistance substitutions in different subtypes of HIV integrase. J. Virol. 2015, 89, 3163-3175. [CrossRef]

16. Yoshinaga, T.; Kobayashi, M.; Seki, T.; Miki, S.; Wakasa-Morimoto, C.; Suyama-Kagitani, A.; Kawauchi-Miki, S.; Taishi, T.; Kawasuji, T.; Johns, B.A.; et al. Antiviral characteristics of GSK1265744, an HIV integrase inhibitor dosed orally or by long-acting injection. Antimicrob. Agents Chemother. 2015, 59, 397-406. [CrossRef] [PubMed]

17. Yoshinaga, T.; Seki, T.; Miki, S.; Miyamoto, T.; Suyama-Kagitani, A.; Kawauchi-Miki, S.; Kobayashi, M.; Sato, A.; Stewart, E.; Underwood, M.; et al. Novel secondary mutations C56S and G149A confer resistance to HIV-1 integrase strand transfer inhibitors. Antivir. Res. 2018, 152, 1-9. [CrossRef]

18. Oliveira, M.; Ibanescu, R.I.; Anstett, K.; Mesplede, T.; Routy, J.P.; Robbins, M.A.; Brenner, B.G.; The Montreal Primary HIV (PHI) Cohort Study Group. Selective resistance profiles emerging in patient-derived clinical isolates with cabotegravir, bictegravir, dolutegravir, and elvitegravir. Retrovirology 2018, 15, 56. [CrossRef]

19. Margolis, D.A.; Brinson, C.C.; Smith, G.H.R.; de Vente, J.; Hagins, D.P.; Eron, J.J.; Griffith, S.K.; Clair, M.H.S.; Stevens, M.C.; Williams, P.E.; et al. Cabotegravir plus rilpivirine, once a day, after induction with cabotegravir plus nucleoside reverse transcriptase inhibitors in antiretroviral-naive adults with HIV-1 infection (LATTE): A randomised, phase 2b, dose-ranging trial. Lancet Infect. Dis. 2015, 15, 1145-1155. [CrossRef]

20. Malet, I.; Subra, F.; Charpentier, C.; Collin, G.; Descamps, D.; Calvez, V.; Marcelin, A.G.; Delelis, O. Mutations Located outside the Integrase Gene Can Confer Resistance to HIV-1 Integrase Strand Transfer Inhibitors. mBio 2017, 8, e00922-17. [CrossRef]

21. Wijting, I.E.A.; Lungu, C.; Rijnders, B.J.A.; van der Ende, M.E.; Pham, H.T.; Mesplede, T.; Pas, S.D.; Voermans, J.J.C.; Schuurman, R.; van de Vijver, D.; et al. HIV-1 Resistance Dynamics in Patients With Virologic Failure to Dolutegravir Maintenance Monotherapy. J. Infect. Dis. 2018, 218, 688-697. [CrossRef]

22. Hikichi, Y.; Van Duyne, R.; Pham, P.; Groebner, J.L.; Wiegand, A.; Mellors, J.W.; Kearney, M.F.; Freed, E.O. Mechanistic Analysis of the Broad Antiretroviral Resistance Conferred by HIV-1 Envelope Glycoprotein Mutations. mBio 2021, 12, e03134-20. [CrossRef]

23. Van Duyne, R.; Kuo, L.S.; Pham, P.; Fujii, K.; Freed, E.O. Mutations in the HIV-1 envelope glycoprotein can broadly rescue blocks at multiple steps in the virus replication cycle. Proc. Natl. Acad. Sci. USA 2019, 116, 9040-9049. [CrossRef] [PubMed]

24. Wei, Y.; Sluis-Cremer, N. Mutations in the HIV-13'-Polypurine Tract and Integrase Strand Transfer Inhibitor Resistance. Antimicrob. Agents Chemother. 2021, 65, 65. [CrossRef] [PubMed]

25. Ferris, A.L.; Wu, X.; Hughes, C.M.; Stewart, C.; Smith, S.J.; Milne, T.A.; Wang, G.G.; Shun, M.C.; Allis, C.D.; Engelman, A.; et al. Lens epithelium-derived growth factor fusion proteins redirect HIV-1 DNA integration. Proc. Natl. Acad. Sci. USA 2010, 107, 3135-3140. [CrossRef] [PubMed]

26. Smith, S.J.; Hughes, S.H. Rapid screening of HIV reverse transcriptase and integrase inhibitors. J. Vis. Exp. 2014, 86, e51400. [CrossRef]

27. Smith, S.J.; Zhao, X.Z.; Passos, D.O.; Pye, V.E.; Cherepanov, P.; Lyumkis, D.; Burke, T.R., Jr.; Hughes, S.H. HIV-1 Integrase Inhibitors with Modifications That Affect Their Potencies against Drug Resistant Integrase Mutants. ACS Infect. Dis. 2021, 7, 1469-1482. [CrossRef]

28. Smith, S.J.; Zhao, X.Z.; Passos, D.O.; Lyumkis, D.; Burke, T.R., Jr.; Hughes, S.H. HIV-1 Integrase Inhibitors That Are Active against Drug-Resistant Integrase Mutants. Antimicrob. Agents Chemother. 2020, 64, e00611-20. [CrossRef] 
29. Zhao, X.Z.; Smith, S.J.; Maskell, D.P.; Metifiot, M.; Pye, V.E.; Fesen, K.; Marchand, C.; Pommier, Y.; Cherepanov, P.; Hughes, S.H.; et al. HIV-1 Integrase Strand Transfer Inhibitors with Reduced Susceptibility to Drug Resistant Mutant Integrases. ACS Chem. Biol. 2016, 11, 1074-1081. [CrossRef]

30. Zhao, X.Z.; Smith, S.J.; Maskell, D.P.; Metifiot, M.; Pye, V.E.; Fesen, K.; Marchand, C.; Pommier, Y.; Cherepanov, P.; Hughes, S.H.; et al. Structure-Guided Optimization of HIV Integrase Strand Transfer Inhibitors. J. Med. Chem. 2017, 60, 7315-7332. [CrossRef]

31. Smith, S.J.; Pauly, G.T.; Akram, A.; Melody, K.; Ambrose, Z.; Schneider, J.P.; Hughes, S.H. Rilpivirine and Doravirine Have Complementary Efficacies Against NNRTI-Resistant HIV-1 Mutants. J. Acquir. Immune Defic. Syndr. 2016, 72, 485-491. [CrossRef]

32. Smith, S.J.; Pauly, G.T.; Akram, A.; Melody, K.; Rai, G.; Maloney, D.J.; Ambrose, Z.; Thomas, C.J.; Schneider, J.T.; Hughes, S.H. Rilpivirine analogs potently inhibit drug-resistant HIV-1 mutants. Retrovirology 2016, 13, 11. [CrossRef] [PubMed]

33. Smith, S.J.; Pauly, G.T.; Hewlett, K.; Schneider, J.P.; Hughes, S.H. Structure-based non-nucleoside inhibitor design: Developing inhibitors that are effective against resistant mutants. Chem. Biol. Drug Des. 2021, 97, 4-17. [CrossRef] [PubMed]

34. Smith, S.J.; Zhao, X.Z.; Burke, T.R., Jr.; Hughes, S.H. HIV-1 Integrase Inhibitors That Are Broadly Effective against Drug-Resistant Mutants. Antimicrob. Agents Chemother. 2018, 62, 62. [CrossRef]

35. Sluis-Cremer, N.; Tachedjian, G. Mechanisms of inhibition of HIV replication by non-nucleoside reverse transcriptase inhibitors. Virus Res. 2008, 134, 147-156. [CrossRef] [PubMed]

36. Betancor, G.; Alvarez, M.; Marcelli, B.; Andres, C.; Martinez, M.A.; Menendez-Arias, L. Effects of HIV-1 reverse transcriptase connection subdomain mutations on polypurine tract removal and initiation of (+)-strand DNA synthesis. Nucleic Acids Res. 2015, 43, 2259-2270. [CrossRef]

37. Biondi, M.J.; Beilhartz, G.L.; McCormick, S.; Gotte, M. N348I in HIV-1 reverse transcriptase can counteract the nevirapinemediated bias toward RNase H cleavage during plus-strand initiation. J. Biol. Chem. 2010, 285, 26966-26975. [CrossRef]

38. Grobler, J.A.; Dornadula, G.; Rice, M.R.; Simcoe, A.L.; Hazuda, D.J.; Miller, M.D. HIV-1 reverse transcriptase plus-strand initiation exhibits preferential sensitivity to non-nucleoside reverse transcriptase inhibitors in vitro. J. Biol. Chem. 2007, 282, 8005-8010. [CrossRef]

39. Hare, S.; Maertens, G.N.; Cherepanov, P. 3'-processing and strand transfer catalysed by retroviral integrase in crystallo. EMBO J. 2012, 31, 3020-3028. [CrossRef] [PubMed]

40. Fujiwara, T.; Mizuuchi, K. Retroviral DNA integration: Structure of an integration intermediate. Cell 1988, 54, 497-504. [CrossRef]

41. Miller, M.D.; Farnet, C.M.; Bushman, F.D. Human immunodeficiency virus type 1 preintegration complexes: Studies of organization and composition. J. Virol. 1997, 71, 5382-5390. [CrossRef]

42. Brown, P.O.; Bowerman, B.; Varmus, H.E.; Bishop, J.M. Retroviral integration: Structure of the initial covalent product and its precursor, and a role for the viral IN protein. Proc. Natl. Acad. Sci. USA 1989, 86, 2525-2529. [CrossRef]

43. Engelman, A.; Mizuuchi, K.; Craigie, R. HIV-1 DNA integration: Mechanism of viral DNA cleavage and DNA strand transfer. Cell 1991, 67, 1211-1221. [CrossRef]

44. Hu, W.S.; Hughes, S.H. HIV-1 reverse transcription. Cold Spring Harb. Perspect. Med. 2012, 2, a006882. [CrossRef]

45. Varadarajan, J.; McWilliams, M.J.; Hughes, S.H. Treatment with suboptimal doses of raltegravir leads to aberrant HIV-1 integrations. Proc. Natl. Acad. Sci. USA 2013, 110, 14747-14752. [CrossRef] [PubMed]

46. Oh, J.; Chang, K.W.; Hughes, S.H. Mutations in the U5 sequences adjacent to the primer binding site do not affect tRNA cleavage by rous sarcoma virus RNase $\mathrm{H}$ but do cause aberrant integrations in vivo. J. Virol. 2006, 80, 451-459. [CrossRef]

47. Hang, J.Q.; Li, Y.; Yang, Y.; Cammack, N.; Mirzadegan, T.; Klumpp, K. Substrate-dependent inhibition or stimulation of HIV RNase $\mathrm{H}$ activity by non-nucleoside reverse transcriptase inhibitors (NNRTIs). Biochem. Biophys. Res. Commun. 2007, 352, 341-350. [CrossRef]

48. Radzio, J.; Sluis-Cremer, N. Efavirenz accelerates HIV-1 reverse transcriptase ribonuclease H cleavage, leading to diminished zidovudine excision. Mol. Pharmacol. 2008, 73, 601-606. [CrossRef]

49. Shaw-Reid, C.A.; Feuston, B.; Munshi, V.; Getty, K.; Krueger, J.; Hazuda, D.J.; Parniak, M.A.; Miller, M.D.; Lewis, D. Dissecting the effects of DNA polymerase and ribonuclease $\mathrm{H}$ inhibitor combinations on HIV-1 reverse-transcriptase activities. Biochemistry 2005, 44, 1595-1606. [CrossRef] [PubMed]

50. Sarafianos, S.G.; Marchand, B.; Das, K.; Himmel, D.M.; Parniak, M.A.; Hughes, S.H.; Arnold, E. Structure and function of HIV-1 reverse transcriptase: Molecular mechanisms of polymerization and inhibition. J. Mol. Biol. 2009, 385, 693-713. [CrossRef] 